\title{
DETECTING EGFR MUTATIONS IN PATIENTS WITH NON-SMALL CELL LUNG CANCER
}

Hammoudeh $\mathrm{ZA}^{1,2, *}$, Antonova $\mathrm{O}^{1}$, Staneva $\mathrm{R}^{1,2}$, Nikolova $\mathrm{D}^{1}$, Kyuchukov $\mathrm{Y}^{2}$, Penev $\mathrm{A}^{2}$, Mintchev $\mathrm{T}^{2}$, Koleva $\mathrm{V}^{2}$, Hadjidekova $\mathrm{S}^{1}$, Toncheva $\mathrm{D}^{1,2}$

*Corresponding Author: Zora A. Hammoudeh, Molecular Biologist, Department of Medical Genetics, Medical University Sofia, 2 Zdrave Str., 1431 Sofia, Bulgaria. Tel: +359-2-917-2735. Mobile:+359-88-943-0505. E-mail: zorahammoudeh@yahoo.com

\begin{abstract}
Mutations in the receptor of the epidermal growth factor receptor $(E G F R)$ in non-small cell lung cancer (NSCLC) are used as biomarkers for predicting the response of treatment with EGFR tyrosine kinase inhibitors (EGFR TKIs). Non-small cell lung cancer patients usually have activating EGFR mutations that leads to a very good response when they are treated with EGFR TKIs. Our tumor samples were examined for the presence of sensitive mutations in the EGFR gene, resistant mutations or the absence of mutations. To identify the types of the mutation, we used a real-time polymerase chain reaction (RT-PCR) method. Additionally, we evaluated the frequency of EGFR mutations and their association with smoking status, gender and histology. The tumor samples $(n=551)$ were tested for 29 somatic mutations in the EGFR gene. Sensitive mutations in the EGFR genes were found in 55 NSCLC samples (10.0\%). The prevalence of EGFR mutations was much higher for females than for males (27.1 vs. 3.9\%, $p$ $<0.001)$. The prevalence of $E G F R$ mutations was greater in subjects who had never smoked than in smokers (15.0 vs. $6.08 \%, p<0.003)$. Additionally, the frequency of $E G F R$ mutations was higher in adenocarcinomas than in other histological types (14.9 vs. $5.1 \% ; p<0.001)$. Our results show that activating mutations on the $E G F R$ gene are more frequent in females than in males, in adenocarcinoma than other histological types and in non smokers than smokers.

Keywords: Adenocarcinoma; Epidermal growth factor receptor (EGFR); Non-small cell lung cancer (NSCLC); Mutations; Real-time polymerase chain reaction (RT-PCR); Target therapy.
\end{abstract}

\footnotetext{
${ }^{1}$ Department of Medical Genetics, Medical University, Sofia, Bulgaria

2 Acibadem City Clinic Tokuda Hospital, Sofia, Bulgaria
}

\section{INTRODUCTION}

In Bulgaria, lung cancer is a major health problem; it is more frequent in men than in women and most of the patients are diagnosed when they are in an advanced stage. Non-small-cell lung cancer (NSCLC) is the most common form of lung cancer $(85.0 \%$ of the cases) and it is the leading cause of death for male and female patients. As reported by the Bulgarian National Cancer Registry, NSCLC is the most common malignancy in men (19.1\%) and the seventh in women $(5.1 \%)$ [1,2]. Patients with NSCLC must be tested for prognostic markers associated with the survival of the patient and predictive biomarkers associated with the effect of the therapeutics. The target therapy contributes to the therapeutic approach according to specific genetic abnormalities in the tumor tissue. A lot of genes with predictive and prognostic significance in NSCLC are involved in the signaling pathway EGFR/ $K R A S / R A F / M E K / M E K / E R K$ [3]. The epidermal growth factor receptor $(E G F R)$ gene encodes a protein that is a transmembrane glycoprotein, a member of the protein kinase family. The receptor for members of the EGFR family, has three domains: extracellular, trans membrane and intracellular. When the ligand is attached to the receptor a cascade is induced, tyrosine is autophosphorylated and the activity of tyrosine kinase is increased. The Ras/ Raf/MEK/ERK cascade transmits signals to transcription factors, which regulate gene expression and the activity of proteins involved in apoptosis. Mutations in the EGFR gene lead to over expression of the protein and had been associated with development of lung cancer, especially NSCLC. Sensitive mutations in the EGFR gene, such as mutations, deletions in exon 19, and the point mutation L858R in exon 21 , have been reported in $80.0 \%$ of cases. They are found in $10.0-15.0 \%$ of the patients with adenocarcinomas and only $3.0 \%$ of other histological 
types. In advanced NSCLC, the presence of an activating mutation in EGFR gene confers better prognosis and predicts the sensitivity of tumor cells to EGFR tyrosine kinase inhibitors (TKIs) [4,5]. In Bulgaria, it is recommended that patients with adenocarcinoma be tested for the EGFR gene mutations, so they can be given EGFR TKI as a first-line therapy instead of chemotherapy. The mutations, deletion in exon 19 and L858R in exon 21 in the EGFR gene are associated with sensitivity to TKIs such as gefitinib [6]. Both mutations show increased sensitivity to first generation EGFR TKIs and they are the most frequent mutations in NSCLC [7]. Overall, mutations in the EGFR gene are more frequent in tumors classified as adenocarcinoma, in female patients who have never smoked. Therefore, those patients have the highest response rates to gefitinib $[8,9]$.

Many molecular technologies are used in the diagnostic laboratories for the evaluation of the EGFR gene mutations. In this series of samples from Bulgarian NSCLC patients, we applied a real-time polymerase chain reaction (RT-PCR) analysis of DNA extracted from formalin-fixed paraffin-embedded tissue (FFPE).

We present our data for the EGFR gene mutations, using RT-PCR kit (therascreen EGFR RGQ PCR kit) amplification refractory mutation system (ARMS) and Scorpions therascreen ${ }^{\circledR}$ EGFR test; Qiagen Ltd., Manchester, Greater Manchester, UK). The kit is optimized for in vitro diagnostics and detects the following mutations in the EGFR gene: exon 19 deletions, L858R, L861Q, G719X, S768I, exon 20 insertions, and the point mutation T790M.

\section{MATERIALS AND METHODS}

Tumor samples from 551 Bulgarian patients diagnosed with NSCLC have been collected for the last 5 years. The patients were aged between 24 and 84 years old and the average age was 63 . The gender ratio in the tested group was 407 (73.9\%) males and 144 females (26.1\%). All procedures were supervised and approved by the hospital's Ethics Committee. For examination of the samples, the patients provided a signed written informed consent.

DNA was extracted from FFPE NSCLC samples from primary tumors by QIAamp DNA FFPE Tissue Kit (Qiagen Ltd.) for genomic DNA purification. The concentrations of the DNA samples were measured by NanoDrop Lite spectrophotometer system (Thermo Fisher Scientific, Waltham, MA, USA).

The therascreen EGFR RGQ PCR Kit (Qiagen Ltd.) was custom-made for detecting 29 somatic mutations in exons 18-21 of the EGFR gene using a RT-PCR technology. The amplification reaction was done on the Rotor-Gene Q instrument (Qiagen Ltd.). For detecting the mutations with RT-PCR, the assay used two technologies, ARMS and Scorpions (Qiagen Ltd.). Mutation-specific amplification was performed using the ARMS technique, meanwhile detection of amplification was performed using Scorpions PCR primers linked to a probe. After completing the PCR run, each DNA sample was analyzed for the presence of EGFR gene mutations, or not, by Rotor-Gene Q Series (Qiagen Ltd.). If there was amplification on one or more mutation reaction in the sample, the difference between the mutation cycle threshold $\left(\mathrm{C}_{\mathrm{T}}\right)$ and control $\left(\mathrm{C}_{\mathrm{T}}\right)$ from the same sample was used to calculate $\mathrm{C}_{\mathrm{T}}$ values. Then we compare the $\mathrm{C}_{\mathrm{T}}$ value for the sample with the cutoff point for the assay in a table according to the manufacturer's guideline (Qiagen Ltd.).

We used the $\chi^{2}$ tests to evaluate the association between EGFR gene mutations and clinicopathological features, such as gender, smoking status and histological type. The statistical analysis was performed between the positive EGFR patient's groups, divided into males $v s$. females, smokers $v s$. non smokers and adenocarcinomas and other histological types (squamous cell carcinoma and large cell carcinoma). All the statistical analyses were performed using the R Core Team (2013) software (http:// www.R-project.org/.) The results were considered statistically significant at a $p$ value of less than 0.05 .

\section{RESULTS}

The NSCLC samples were classified by an experienced pathologist into $50.1 \%(n=276)$ adenocarcinoma and $49.9 \%(n=275)$ other histological types. Distribution by stage was as follow: 38 patients were diagnosed with stage IIIB and 513 were stage IV. There were 338 smokers $(61.3 \%)$ and 213 were non smokers $(38.7 \%)$. The risk of having lung cancer for smokers increased with the number of cigarettes smoked per day or duration of smoking [10]. The clinical characteristics of the patients are shown in Table 1 .

Mutational status was determined according to the manufacturer's protocol. All samples analyzed had an internal control $\mathrm{C}_{\mathrm{T}}$ value in the reference range 23-30, 69 . Positive amplification for EGFR mutational assay was considered in the case of $\mathrm{C}_{\mathrm{T}}$ value within the range of 15-40. The $\Delta \mathrm{C}_{\mathrm{T}}$ value for each mutation sample showing positive amplification was calculated by the formula: $\Delta \mathrm{CT}=$ mutation $\mathrm{C}_{\mathrm{T}}$-control $\mathrm{C}_{\mathrm{T}}$ and compared to the reference provided by the manufacturer (Figure 1). The EGFR gene mutations 


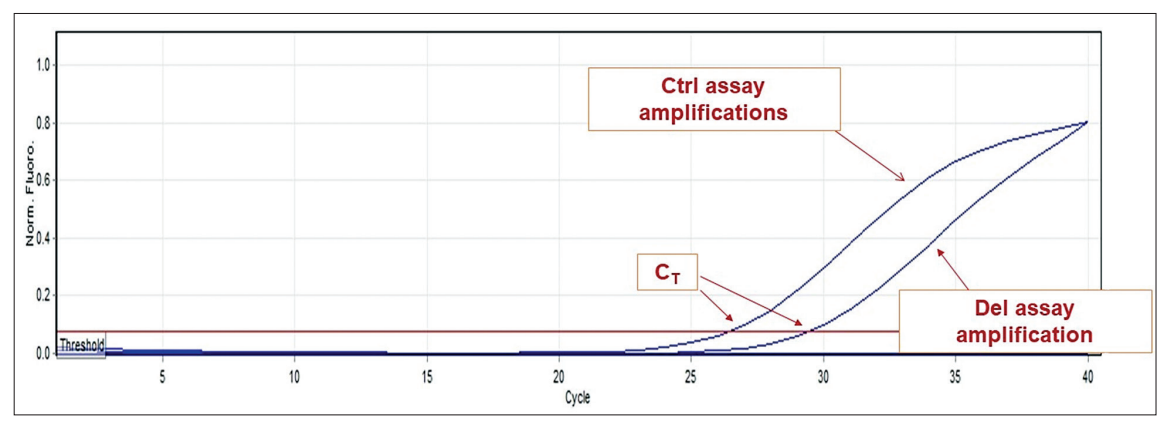

Figure 1. Plot shows EGFR positive samples for the exon 19 deletion; amplification of the internal control (Ctrl assay) with $\mathrm{C}_{\mathrm{T}} 26.45$ and amplification for mutational assay (del assay) with $\mathrm{C}_{\mathrm{T}}$ 29.42. $\Delta \mathrm{C}_{\mathrm{T}}=2.97$ (calculated by the formula $\Delta \mathrm{C}_{\mathrm{T}}=$ mutation $\mathrm{C}_{\mathrm{T}}$-control $\mathrm{C}_{\mathrm{T}}$ ). The $\Delta \mathrm{C}_{\mathrm{T}}$ cutoff value for this mutational assay was 9.06 .

Table 1. Clinicopathological features of the 551 patients.

\begin{tabular}{|l|c|c|c|c|}
\hline Clinicopathological Features & Total Patients $(\boldsymbol{n})$ & \multicolumn{2}{|c|}{ Patients with Mutations or Wild-Type $(\boldsymbol{n})$} & $\boldsymbol{p}$ Value \\
\hline & & Mutations & Wild-Type & \\
\hline Gender: & & & & $<0.0001$ \\
$\quad$ males & 407 & 16 & 391 & \\
$\quad$ females & 144 & 39 & 105 & 0.000232 \\
\hline Histology: & 276 & 41 & 235 & \\
$\quad$ adenocarcinomas & 275 & 14 & 261 & 0.002807 \\
$\quad$ other types & 338 & 23 & 315 & 181 \\
\hline Smoking history: & 213 & 32 & & \\
$\quad$ smokers & & & & \\
$\quad$ non smokers & & & & \\
\hline
\end{tabular}

Table 2. Types of the mutations detected.

\begin{tabular}{|l|c|c|}
\hline Mutations Detected & $\begin{array}{c}\text { Patients } \\
(\boldsymbol{n})\end{array}$ & $\mathbf{\%}$ \\
\hline Deletions in exon 19 & 31 & 56.4 \\
\hline L858R & 20 & 36.4 \\
\hline Insertions in exon 20 & 2 & 3.6 \\
\hline Deletions in exon 19 and T790M & 1 & 1.8 \\
\hline Deletions in exon 19 and S768I & 1 & 1.8 \\
\hline
\end{tabular}

were found in $10.0 \%$ of the NSCLC samples $(n=55)$ using the therascreen EGFR assay (Qiagen Ltd.) (Table 2).

\section{DISCUSSION}

In our study, exon 19 deletions and the point mutation L858R in exon 21 constituted $92.7 \%$ of all EGFR gene mutations, which confirms the findings of previous studies [11]. Deletions in exon 19 of the $E G F R$ gene were detected in $56.3 \%(n=31)$ of all mutated samples, while L858R was detected in $36.4 \%(n=20)$. All the EGFR gene exon 19 deletions positive patients had stage IV cancer. The L858R mutation was found in $36.4 \%(n=20)$ of EGFR positive cases, with $90.0 \%(n=18)$ having stage IV and $10.0 \%(n$ $=2$ ) stage IIIb. Insertions in exon 20 represented 3.6\% $(n=2)$ of all detected mutations. The rarest cases in our cohort, in concordance with previously reported results in the literature, were the double mutants, representing 3.6\% $(n=2)$. A T790M point mutation was detected in only one sample together with a deletion in exon 19. In the other double mutant sample, a combination of a S768I mutation and a deletion in exon 19 was detected.

According to smoking status, there was a higher prevalence of the EGFR gene mutation positive cases in smokers. In our cohort, the EGFR gene mutations were found in $15.0 \%(n=32)$ patients who had never smoked and in $6.8 \%(n=23)$ smokers $(p<0.003)$.

The prevalence of the EGFR gene mutations was higher in females than in males. Female to male ratio in the EGFR gene mutation positive cases in our cohort was 2.4: 1 , with $27.1 \%(n=39)$ positive cases in female samples and $3.9 \%(n=16)$ in males $(p<0.001)$. The frequency of the mutations in adenocarcinomas was higher than in 
other histological types with a statistically different (14.9 vs. $5.1 \%, p<0.001$ ) frequency.

Multiple studies have shown that mutations in the EGFR gene TK domain are used as predictors for the therapeutic response and the progression-free survival benefit of EGFR treatment [12]. Many studies showed that EGFR gene mutations are more common in adenocarcinomas in women and non smokers [13]. Our results are consistent with previous studies.

Our results showed that $10.0 \%$ of the advanced NSCLC patients in Bulgaria carried mutations in the EGFR gene. The statistical analysis showed the difference in $E G F R$ gene mutation rate between female and male patients to be statistically significant $(p<0.001)$. Likewise, the analysis showed the difference in EGFR gene mutation rate between patients with adenocarcinomas and patients with other histological types (such as squamous cell carcinoma and large cell carcinoma) to be significant ( $p=$ $0.0001)$. Whereas the results showed the difference in EGFR gene mutation rate between non smoking patients and patients who smoked to be statistically significant ( $p$ $<0.003)$.

In our cohort, exon 19 deletions and the L858R mutation represented $92.7 \%$ of the detected mutations conveying sensitivity to TKIs. Deletion in the EGFR gene exon 19 was found in 23 lung adenocarcinomas, eight in other histological types. The L858R EGFR gene mutation was found in 16 lung adenocarcinomas, four in other histological types. The remaining $7.3 \%$ of the mutations we detected are insertions in exon 20 and double mutations, exon 19 deletion and T790M, and exon 19 deletion and S768I. The EGFR gene exon 19 deletion and S768I double mutation was detected in lung adenocarcinoma, and the EGFR gene exon 19 deletion and T790M double mutation was found in a squamous cell carcinoma. The $E G F R$ gene exon 20 insertions were found in two samples, one lung adenocarcinoma and one squamous cell carcinoma.

Previous studies have shown that NSCLC patients whose tumors have sensitive mutation in the EGFR gene respond better than those with a wild-type tumor variant to drugs that target the TK domain of the gene. Therefore, according to all therapeutic guidelines, it is mandatory to determine the mutational status of the EGFR gene in patients with NSCLC in order to assess their eligibility for TKI treatment $[14,15]$. The EGFR gene exon 19 deletions and L858R mutation convey sensitivity to first-generation EGFR TKIs [8]. The T790M mutation predicts resistance to first-generation EGFR TKIs.

\section{CONCLUSIONS}

Our results show that in the Bulgarian NSCLC population the frequency of $E G F R$ gene mutations is in the lower range of the one reported in other European populations. The EGFR gene mutation status can be accurately and quickly determined by the commercially available RTPCR assays. Our results showed that activating EGFR gene mutations are statistically more prevalent in women $v s$. men, in adenocarcinomas vs. other histological types and in non smokers $v s$. smokers. The commercially available RT-PCR assays efficiently detect the clinically significant EGFR gene mutations and are a first-tier test to determine EGFR status in a routine diagnostic setting.

Declaration of Interest. The authors report no conflicts of interest. The authors alone are responsible for the content and writing of this article.

\section{REFERENCES}

1. Chilingirova N, Hammoudeh Z, Balabanski L, Ivanov $\mathrm{S}$, Vazharova R, Nikolova D, et al. TruSight Cancer Sequencing Panel reveals pharmacogenetic variants associated with sensitivity to chemotherapy in lung cancer. memo Magazine of European Medical Oncology. 2016; 9(1): 30-38 (https://link.springer.com/ article/10.1007/ s12254-015-0244-2.

2. Jemal A, Siegel R, Ward E, Hao Y, Xu J, Murray T, et al. Cancer statistics, 2008. CA Cancer J Clin. 2008; 58(2): 71-96.

3. Gandhi J, Zhang J, Xie Y, Soh J, Shigematsu H, Zhang $\mathrm{W}$, et al. Alterations in genes of the EGFR signaling pathway and their relationship to EGFR tyrosine kinase inhibitor sensitivity in lung cancer cell lines. Plos One. 2009; 4(2): e4576.

4. Sadowska AM, Nowé V, Janssens A, Boeykens E, De Backer WA, Germonpré PR. Customizing systemic therapy in patients with advanced non-small cell lung cancer. Ther Adv Med Oncol. 2011; 3(4): 207-218.

5. Rosell R, Carcereny E, Gervais R, Vergnenegre A, Massuti B, Felip E, et al. Erlotinib versus standard chemotherapy as first-line treatment for European patients with advanced EGFR mutation-positive nonsmall-cell lung cancer (EURTAC): A multicentre, open-label, randomised phase 3 trial. Lancet Oncol. 2012; 13(3): 239-246. 
6. Lynch TJ, Bell DW, Sordella R, Gurubhagavatula S, Okimoto RA, Brannigan BW, et al. Activating mutations in the epidermal growth factor receptor underlying responsiveness of non-small-cell lung cancer to gefitinib. N Engl J Med. 2004; 350(21): 2129-2139.

7. Gazdar AF. Activating and resistance mutations of EGFR in non-small-cell lung cancer: role in clinical response to EGFR tyrosine kinase inhibitors. Oncogene. 2009; 28(Suppl 1): S24-S31.

8. Pao W, Miller V, Zakowski M, Doherty J, Politi K, Sarkaria I, et al., EGF receptor gene mutations are common in lung cancers from "never smokers" and are associated with sensitivity of tumors to gefitinib and erlotinib. Proc Natl Acad Sci USA. 2004; 101(36): 13306-13311.

9. Jänne PA, Gurubhagavatula S, Yeap BY, Lucca J, Ostler P, Skarin AT, et al. Outcomes of patients with advanced non-small cell lung cancer treated with gefitinib (ZD1839, 'Iressa') on an expanded access study. Lung Cancer. 2004; 44(2): 221-230.

10. Khuder SA. Effect of cigarette smoking on major histological types of lung cancer: A meta-analysis. Lung Cancer. 2001; 31(2-3): 139-148.
11. Sharma SV, Bell DW, Settleman J, Haber DA. Epidermal growth factor receptor mutations in lung cancer. Nat Rev Cancer. 2007; 7(3): 169-181.

12. Maemondo M, Inoue A, Kobayashi K, Sugawara S, Oizumi S, Isobe $\mathrm{H}$, et al. Gefitinib or chemotherapy for non-small-cell lung cancer with mutated EGFR. N Engl J Med. 2010; 362(25): 2380-2388.

13. Jänne PA, Wang X, Socinski MA, Crawford J, Stinchcombe TE, Gu L, et al., Randomized phase II trial of erlotinib alone or with carboplatin and paclitaxel in patients who were never or light former smokers with advanced lung adenocarcinoma: CALGB 30406 Trial. J Clin Oncol. 2012; 30(17): 2063-2069.

14. Hirsch FR, Bunn PA Jr. EGFR testing in lung cancer is ready for prime time. Lancet Oncol. 2009; 10(5): 432-433.

15. Paez JG, Jänne PA, Lee JC, Tracy S, Greulich H, Gabriel S, et al. EGFR mutations in lung cancer: Correlation with clinical response to gefitinib therapy. Science. 2004; 304(5676): 1497-1500. 